\title{
Quality of nursing care provided for preterm neonates of low birth weight with intraventricular hemorrhage
}

Fathia Zaky Mohamed

Assistant Professor of pediatric Nursing, Faculty of Nursing, Assiut University

\begin{abstract}
Intraventricular hemorrhage (IVH) is one of the major complications in premature infants which continue to pose challenges in neonatal intensive care units (NICUs) despite advances and numerous efforts to prevent and its management is quite challenging. The aim of this study was to investigate quality of nursing care provided for preterm neonates of low birth weight with intraventricular hemorrhage. A Descriptive research Design was utilized in this study which carried out at Neonatal Intensive Care Unit (NICU) of Assiut University Children Hospital. A convenience Sample of (51) nurses providing care for (75) preterm neonates of low birth weight with intraventricular hemorrhage and their mothers who met the Inclusion criteria entered the study were participated in the current study. Two tools were used in this study, a structured interview questionnaire and an observational check-list. Results: More than half of studied nurses (50.98\%, 56.86\% and 58.82\%) in the morning, afternoon and evening shifts respectively had good scores of nursing care. Conclusions that, the overall quality of nursing care provided by the studied nurses for preterm neonates with intraventricular hemorrhage was around average. The study Recommended providing quality improvement training programs for all nurses working in neonatal intensive care units
\end{abstract}

\section{Keywords: Quality Of Nursing Care, Preterm Neonates \& Intraventricular Hemorrhage.}

\section{Introduction}

Intraventricular hemorrhage (IVH) remains one of many devastating consequences of prematurity that have both acute and long-term neurologic squeals which place a huge emotional and financial burden on neonates and their families, health care systems, education and government resources, as the number of very preterm infants $(<32$ weeks of gestational age) has increased over the last few years and its management is quite challenging despite advances in neonatal intensive care (Christian, et al., 2016 \& Karen, et al., 2017)

Intraventricular hemorrhage (IVH) is bleeding due to rupture of blood vessels within the germinal matrix tissue of the developing brain into the ventricular system and it ranges in severity from grade I to the most severe grade IV which include ; 0 - no bleeding, I- germinal matrix only, II- germinal matrix with blood in the ventricles ,III - germinal matrix with blood in the ventricles and hydrocephalus (ventricular dilatation ) and IV- Intraventricular and parenchyma bleeding (other than germinal matrix) (Hockenberry \& Wilson, 2015)

The incidence for IVH grades I-IV is around $27 \%$ in neonates weighing less than 1500 g. About $90 \%$ cases of intraventricular hemorrhage occur within the first 3 days of the newborn's life and in $20-40 \%$ of IVH cases become more extended, during first week of life. In the majority of cases involving mild bleeding (classified as grade 1 and grade 2), no clinical effects are observed, usually resolve themselves and cause no long-term problems.
Approximately $60 \%$ of premature infants with grade III and IV were strongly associated with an adverse outcome including cognitive disabilities such as cerebral palsy and mental retardation and death (Allen, 2013 \& Szpecht, et al., 2016)

Clinical features of intraventricular hemorrhage include decreased spontaneous movement, hypotonia, alteration of consciousness, change in eye movement, disturbance in respiratory status, fall in hematocrit, rise of bilirubin levels and rare catastrophic presentation as stupor, coma, apnea decerebrate posturing, seizures, dilated pupil, bulging fontanel, irregular respiration, increased ventilatory requirement, hypotension, bradycardia and metabolic acidosis According to the guidelines of the American Academy of Neurology (AAN), a routine cranial ultrasonographic scans were performed on 3rd, 7th day of life, and once more just before discharging from hospital (Szpecht, et al., 2016 \& Inder, 2018 )

Nursing interventions are especially important during the first $72 \mathrm{~h}$ after birth, since IVH mostly develops during this time window, in which fluctuations in systemic blood pressure as well as postural changes in Preterm infants could lead to alterations in cerebral blood flow (CBF) because they are less able to maintain a relatively constant blood flow to the brain when changes in cerebral perfusion pressure occur. Although apparently harmless, routine care giving events by a neonatology nurse may affect cerebral perfusion and oxygenation in the preterm neonate. (Bolisetty, et al., 2014 \& Karen, et al., 2017). 
Quality of nursing care is the degree of excellence observed in nursing care delivery to patients in accordance with the established nursing care standards (Zhao \& Akkadechanunt, 2011). Quality improvement is a major focus of neonatal health care. It aims at improving neonatal health care outcomes and related activities that contributes to neonatal care nurses. So that, improving and sustaining the quality throughout the continuum of care is an intractable and persistent challenge in hospitals (National Quality Forum, 2011 \& Beattie, et al., 2014).

Neonatology nurses play an important and significant role in nursing care for preterm neonates with intraventricular hemorrhage in which their nursing care focuses on interventions to decrease the risk of bleeding, and supportive care to infants who have bleeding episodes. The neonate is positioned with the head in midline and the head of the bed elevated slightly to prevent or minimize fluctuations in intracranial blood pressure. Neutral thermal environment (NTE) is maintained, as well as oxygenation. Rapid infusions of fluids should be avoided. Blood pressure is monitored closely for fluctuations. The neonate is monitored for signs of pneumothorax because it often precedes IVH (Kenner, \& Ellerbee, 2018)

\section{Significance of the Study}

Intraventricular hemorrhage (IVH) is one of the major complications in premature infants which create a challenge in neonatal intensive care units (NICUs) worldwide and has a substantial impact on the life of affected neonates and their families. Its and resultant hydrocephalus are common causes of neonatal morbidity and mortality among preterm and low-birth-weight infants. Of the extremely premature infants (gestational age [GA] <28 weeks), 20-25\% will develop IVH, with the incidence being inversely proportional to gestational age (GA) (El-Atawi, et al., 2016 \& Karen, 2017)

\section{Aim of the Study}

The aim of this study was to investigate quality of nursing care provided for preterm neonates of low birth weight with intraventricular hemorrhage

\section{Research question}

What is quality of nursing care provided for preterm neonates of low birth weight with intraventricular hemorrhage?

\section{Subjects \& Method \\ Research Design}

Descriptive research design was utilized to achieve the aim of this study.

\section{Operational definitions}

Intraventricular hemorrhage (IVH) is bleeding due to rupture of blood vessels within the germinal matrix tissue of the developing brain into the ventricular system (Hockenberry \& Wilson, 2015).

Quality of nursing care is the degree of excellence observed in nursing care delivery to patients in accordance with the established nursing care standards (Zhao \& Akkadechanunt, 2011).

\section{Setting}

The study was conducted at Neonatal Intensive Care Unit (NICU) of Assiut University Children Hospital.

\section{Sampling}

A convenience sample of (51) neonatal nurses working in Neonatal Intensive Care Unit (NICU) at Assiut University Children Hospital was participated in the current study. Sample included also, all preterm neonates (75) with intraventricular hemorrhage admitted at NICU of Assiut University Children Hospital within six months and their mother's.

\section{Inclusion criteria}

- Each nurse working at Neonatal Intensive Care Unit (NICU) of Assiut University Children Hospital and provide care for preterm neonates of low birth weight with intraventricular hemorrhage.

- Preterm neonates of both sexes who diagnosed with intraventricular hemorrhage, born within less than 24 to 30 weeks of gestation, weighing from less than 750 to $1500 \mathrm{gm}$ and has no multiple congenital anomalies, other brain injuries or central nervous system anomalies.

Tools of data collection:

Two tools were used in this study, a structured interview questionnaire and an observational checklist

Tool 1: A structured interview questionnaire which was developed by the researcher after reviewing related literatures' and it includes five parts:-

Part (1): Biosocial data of studied nurses as age, educational level and Job level, residence, marital status, years of experience and attending previous training about nursing care for preterm neonates with intraventricular hemorrhage

Part (2): Personal characteristics of preterm neonates as name, date of admission, diagnosis, gender, gestational age and weight on admission

Part (3): Personal characteristics of preterm neonates' mothers as age, educational level and occupation.

Part (4): Mother's gynecological and medical data as antenatal care, type of pregnancy, complications during pregnancy, use of medication during pregnancy, chronic disease, place and type of delivery and complications during delivery. 
Part (5): Newborn medical data as gestational age at birth, birth weight, Apgar scoring, Blood transfusion immediately after delivery, congenital anomalies and neonatal complications.

\section{Tool11: An observational check-list}

It formulated on the basis of standard intervention to be performed by Neonatology Intensive Care (NICU) nurses standards of performance for preterm neonates with intraventricular hemorrhage. It was prepared using Hockenberry \& Wilson, (2015) Nursing care of infants and children and VanAesdale \& Upton, (2016) IVH prevention guidelines which consists of different practices that are to be performed during the first 72 hours throughout first week up to 15 days to minimize the effects of the deficit in cerebral blood flow (CBF) auto-regulation and reduce blood flow fluctuations as (head in a midline position, Elevate the head of the bed slightly at 30-degree , Minimum handling of infants, etc.), the total scores of nurses' performance were (54) for all the nursing procedures carried out for the neonates regarding to IVH, checked by done satisfactory, done unsatisfactory or not done .The total quality of care score was calculated by converting score into percentage $\%$ of performance care as follows: done excellent $>70 \%$, done good 70-5o \% and done poor $<50 \%$ (Abd El Fattah \& Zein El Dein, 2012).

\section{Method}

- An official approval was obtained from the administrator of Assiut University Children Hospital and the manager of Neonatal Intensive Care Unit (NICU) after explaining the aim and nature of the study.

\section{Ethical considerations}

Written consent from both nurses and parents of neonates was assured to be participated in the study. Privacy and confidentiality of the data was asserted. Every nurse and parent of neonate was reassured that information obtained would be confidential and used only for the purpose of the study.

\section{Pilot Study}

- A Pilot Study was carried out on $10 \%$ (5) nurses to test the applicability and time consumed to filling the study tools. According to the results of the pilot study, the needed modifications were done, after that the final form was set and then nurses involved in the pilot study were included in the study sample.

- Study tools were developed by the researcher and the validity was tested for (tool I\&II) by exposing them to five experts in both pediatric nursing and medical fields and the reliability was assessed for the second tool; an observational check-list by measuring its inter-rater reliability using test-retest Cronbach's alpha coefficient method. The Cronbach's alpha for the overall check-list was (.90) which indicated good reliability.
- Indirect observation of nursing performance provided for the preterm neonates with intraventricular hemorrhage was done for every nurse in the three shifts (morning, afternoon and evening shifts) by the researcher using the developed observational check-list (tool II). Data collection was done three days per week; the average time taken for observing every nurse ranged from (1-1.5 hours) daily and each interview took about 20 to 25 minutes.

- Interviewing the studied neonates' parents was conducted according to their available time in the morning or afternoon shifts to collect necessary data. The time needed for each interview ranged from 30 to 45 minutes.

\section{Field of the work}

The study was conducted over a period of six months; from the beginning of October 2017 to the end of March 2018. The researcher was available at the study setting three days per week during morning, afternoon and night shifts. Each nurse was individually interviewed using the questionnaire sheet while their performance was assessed by using observational checklists during their actual care provided for neonates with IVH. The average time taken for observing every nurse ranged from (1-1.5 hours) daily and each interview took about 20 to 25 minutes.

\section{Statistical analysis}

The obtained data were coded, analyzed and tabulated using SPSS" ver. 23".Data were presented using descriptive statistics in the form of frequencies and percentages for qualitative variables, means and standard deviations for quantitative variables and Pearson correlation to determine correlation between numeric variables. $\mathrm{P}$ values $<0.05$.Levels are considered statistically significant. 


\section{Results}

Table (1): Percentage distribution of studied preterm neonates related to their personal characteristics and medical data.

\begin{tabular}{|c|c|c|}
\hline Items & NO $(n=75)$ & $\%$ \\
\hline \multicolumn{3}{|l|}{ 1- Gender } \\
\hline Male & 39 & 52 \\
\hline Female & 36 & 48 \\
\hline \multicolumn{3}{|l|}{ 2- Gestational age"wks." } \\
\hline$<24$ & -- & \\
\hline $26-<28$ & 7 & 9.33 \\
\hline $28-<30$ & 40 & 53.33 \\
\hline 30 & 28 & 37.33 \\
\hline \multicolumn{3}{|l|}{ 3- Weight "gm" } \\
\hline$<1500 \mathrm{gm}$ & 54 & 72 \\
\hline$>1500 \mathrm{gm}$ & 18 & 24 \\
\hline Mean \pm SD & \multicolumn{2}{|c|}{$1159.32 \pm 262.8$} \\
\hline \multicolumn{3}{|l|}{ 4- Degree of bleeding } \\
\hline Grade1 & 46 & 61.33 \\
\hline Grade2 & 25 & 33.33 \\
\hline Grade3 & 4 & 5.33 \\
\hline Grade4 & $\overline{--}$ & \\
\hline \multicolumn{3}{|l|}{ 5-Apgar score } \\
\hline $7-10$ & 21 & 28 \\
\hline $7-5$ & 33 & 44 \\
\hline$<4$ & 21 & 28 \\
\hline \multicolumn{3}{|l|}{ 6-Blood transfusion } \\
\hline Yes & 23 & 30.67 \\
\hline No & 52 & 69.33 \\
\hline \multicolumn{3}{|l|}{ 7-Congenital anomalies } \\
\hline Yes & 12 & 16 \\
\hline No & 63 & 84 \\
\hline \multicolumn{3}{|l|}{ * 8- Complication post labor } \\
\hline Asphyxia & 150 & 96 \\
\hline Physiological jaundice & 142 & 90.67 \\
\hline Pathological jaundice & 28 & 37.33 \\
\hline Respiratory distress syndrome (RDS) & 46 & 61.33 \\
\hline Pneumonia & 13 & 17.33 \\
\hline Hypoglycemia & 14 & 18.67 \\
\hline Acidosis & 3 & 4 \\
\hline Convulsion & 27 & 36 \\
\hline Shock & 9 & 12 \\
\hline Sepsis & 5 & 6.67 \\
\hline \multicolumn{3}{|l|}{ 9- Outcome } \\
\hline Improved & 71 & 94.67 \\
\hline Death & 4 & 5.33 \\
\hline
\end{tabular}

*More than one 
Table (2): Percentage distribution of mother's of studied preterm neonates related to their personal characteristics.

\begin{tabular}{|c|c|c|}
\hline Items & $\begin{array}{c}\text { NO } \\
(n=75)\end{array}$ & $\%$ \\
\hline \multicolumn{3}{|l|}{ 1-Age } \\
\hline $20-<25 y r s$ & 16 & 21.33 \\
\hline $25-<30$ yrs. & 40 & 53.33 \\
\hline 30- $<35$ yrs. & 12 & 16.1 \\
\hline $35-40 y r s$. & 7 & 9.33 \\
\hline \multicolumn{3}{|l|}{ 2-Occupation } \\
\hline Works & 26 & 34.67 \\
\hline Housewife & 49 & 65.33 \\
\hline \multicolumn{3}{|l|}{ 3-Educational level } \\
\hline Illiterate & 8 & 10.67 \\
\hline Read\& write & 5 & 6.67 \\
\hline Basic education & 19 & 25.33 \\
\hline Secondary education & 22 & 29.33 \\
\hline University education & 21 & 28 \\
\hline
\end{tabular}

Table (3): Percentage distribution of mother's of studied preterm neonates related to their gynecological (Perinatal) and medical data.

\begin{tabular}{|c|c|c|}
\hline Items & NO $(n=75)$ & $\%$ \\
\hline \multicolumn{3}{|l|}{ 1-Follow up during pregnancy } \\
\hline Yes & 75 & 100 \\
\hline No & -- & \\
\hline \multicolumn{3}{|l|}{ 2-Type of pregnancy } \\
\hline Single & 71 & 94.67 \\
\hline twins & 4 & 5.33 \\
\hline \multicolumn{3}{|l|}{ 3-Complication during pregnancy } \\
\hline Yes & 45 & 60 \\
\hline No & 40 & 53.33 \\
\hline \multicolumn{3}{|l|}{ 4-Type of complications } \\
\hline Bleeding during pregnancy & 29 & 38.67 \\
\hline placental abruption & 11 & 14.76 \\
\hline Pre-eclampsia & 3 & 4 \\
\hline Infection in uterus & 2 & 2.67 \\
\hline \multicolumn{3}{|l|}{ 5-Drugs during pregnancy } \\
\hline Yes & 50 & 66.67 \\
\hline No & 25 & 33 \\
\hline \multicolumn{3}{|l|}{ 6-Chronic disease: } \\
\hline Yes & 42 & 56 \\
\hline No & 25 & 33.33 \\
\hline \multicolumn{3}{|l|}{ * 7-Type of chronic disease: } \\
\hline Diabetes Mellitus & 15 & 20 \\
\hline Hypertension & 27 & 36 \\
\hline Cardiac diseases & 24 & 32 \\
\hline Kidney diseases & -- & \\
\hline Blood diseases & -- & \\
\hline \multicolumn{3}{|l|}{ 8-place of delivery } \\
\hline General hospital & 49 & 65.33 \\
\hline Private hospital & 26 & 34.67 \\
\hline Primary health care center & -- & \\
\hline
\end{tabular}




\begin{tabular}{|c|c|c|}
\hline \multicolumn{1}{|c|}{ Items } & NO (n=75) & \% \\
\hline House & -- & \\
\hline 9-Type of delivery & \multicolumn{2}{|c|}{} \\
\hline Vaginal delivery & 5 & 6.67 \\
\hline C.S & 70 & 93.33 \\
\hline 10-Complications during delivery & \multicolumn{2}{|c|}{} \\
\hline Yes & 72 & 46 \\
\hline No & 3 & 69.33 \\
\hline *11-Type of complication during delivery & \multicolumn{2}{|c|}{} \\
\hline Pre-term labor & 51 & 25.33 \\
\hline Premature rupture of membrane (PROM) & 19 & 33.33 \\
\hline Bleeding before labor & 25 & 8 \\
\hline Length of labor & 6 & 62.67 \\
\hline Bleeding during labor & 47 & \\
\hline
\end{tabular}

* More than one

Table (4): Percentage distribution of studied nurses related to their biosocial data.

\begin{tabular}{|c|c|c|}
\hline Items & NO $(n=51)$ & $\%$ \\
\hline \multicolumn{3}{|l|}{ 1- Age "yrs." } \\
\hline$<20$ yrs. & 10 & 19.6 \\
\hline $20-<30$ yrs. & 13 & 25.49 \\
\hline $30-<40 y r s$. & 19 & 37.25 \\
\hline$\geq 40$ yrs. & 9 & 17.64 \\
\hline Mean \pm SD & \multicolumn{2}{|c|}{$29.45 \pm 9.67$} \\
\hline \multicolumn{3}{|l|}{ 2-Educational level } \\
\hline Diploma of nursing & 17 & 33.33 \\
\hline Institute of nursing & 13 & 25.49 \\
\hline Bachelor's of nursing & 21 & 41.17 \\
\hline \multicolumn{3}{|l|}{ 3-Residence: } \\
\hline Rural & 23 & 45.09 \\
\hline Urban & 28 & 54.90 \\
\hline \multicolumn{3}{|l|}{ 4-Marital status } \\
\hline Single & 13 & 25.49 \\
\hline Married & 33 & 64.70 \\
\hline Widow & -- & \\
\hline Divorced & 5 & 9.80 \\
\hline \multicolumn{3}{|l|}{ 5-Job level } \\
\hline Staff nurse & 46 & 90.20 \\
\hline Specialist & 5 & 9.80 \\
\hline \multicolumn{3}{|l|}{ 6-Years of experience } \\
\hline$<2$ yrs. & 9 & 17.64 \\
\hline $2-<5$ yrs. & 18 & 35.29 \\
\hline $5-<10 \mathrm{yrs}$. & 16 & 31.37 \\
\hline$\geq 10$ yrs. & 8 & 15.68 \\
\hline Mean \pm SD & \multicolumn{2}{|c|}{$12.56 \pm 2.67$} \\
\hline \multicolumn{3}{|c|}{$\begin{array}{l}\text { 7-Attending previous training programs about nursing care for preterm neonates with intraventricular } \\
\text { hemorrhage }\end{array}$} \\
\hline Yes & - & \\
\hline No & 51 & 100 \\
\hline
\end{tabular}


Table (5): Mean score of quality of nursing care provided for studied preterm neonates with intraventricular hemorrhage.

\begin{tabular}{|c|c|c|c|}
\hline \multirow{2}{*}{ Items } & morning Shift & afternoon Shift & evening Shift \\
\hline & $(n=51)$ & $(n=51)$ & $(n=51)$ \\
\hline $\begin{array}{l}\text { 1- Prevention of fluctuations in } \\
\text { cerebral blood flow"22" }\end{array}$ & $15.00 \pm 2.23$ & $13.37 \pm 3.04$ & $13.21 \pm 2.09$ \\
\hline 2- Maintain oxygenation"8” & $6.82 \pm 0.99$ & $7.67 \pm 5.53$ & $7.83 \pm 4.61$ \\
\hline 3- $\quad$ Control infection"6" & $4.76 \pm 1.15$ & $3.74 \pm 0.85$ & $3.25 \pm 0.73$ \\
\hline 4- $\quad$ Feeding"6" & $5.40 \pm 0.74$ & $5.00 \pm 0.46$ & $4.22 \pm 0.36$ \\
\hline 5- $\quad$ Monitoring vital signs"6" & $5.58 \pm 0.56$ & $3.55 \pm 1.00$ & $3.21 \pm 0.89$ \\
\hline 6- Hygienic care"6" & $3.80 \pm 1.34$ & $3.80 \pm 0.66$ & $3.25 \pm 0.43$ \\
\hline Total Score "54": & $41.37 \pm 4.73$ & $37.14 \pm 8.30$ & $36.03 \pm 6.11$ \\
\hline$>37.8(>70 \%)$ Excellent & -- & -- & -- \\
\hline 27-37.8 (50-70\%) Good & $26(50.98 \%)$ & $29(56.86 \%)$ & $30(58.82 \%)$ \\
\hline$<27(<50 \%)$ Poor & $25(49.01 \%)$ & $22(43.13 \%)$ & $21(41.17 \%)$ \\
\hline Mean total score & & $38.18 \pm 5.77$ & \\
\hline
\end{tabular}

Table (6): Correlation between total score of quality of care provided for studied preterm neonates with nurse's age, years of experience and education.

\begin{tabular}{|c|c|c|c|c|c|}
\hline \multicolumn{6}{|c|}{ Correlations } \\
\hline & & Total score & age & Experience & Education \\
\hline \multirow{2}{*}{ Total score } & $\mathbf{R}$ & 1 & $.624^{* * *}$ & -.063 & .530 \\
\hline & $\mathbf{P}$ & --. & .000 & .439 & .006 \\
\hline \multirow{2}{*}{ Age } & $\mathbf{R}$ & $.624^{* * *}$ & 1 & .135 & $-.382^{* *}$ \\
\hline & $\mathbf{P}$ & .000 & -.. & .094 & .594 \\
\hline \multirow{2}{*}{ Experience } & $\mathbf{R}$ & $.563^{* * * *}$ & .135 & 1 & $-.526^{* *}$ \\
\hline & $\mathbf{P}$ & .000 & .094 & -.- & .795 \\
\hline \multirow{2}{*}{ Education } & $\mathbf{R}$ & .530 *** & $-.382^{* 2}$ & $-.526^{* * *}$ & 1 \\
\hline & $\mathbf{P}$ & .006 & .594 & .795 & -.- \\
\hline
\end{tabular}

Table (1): Revealed that, out of 75 low birth weight preterm neonates studied, $71(94.67 \%)$ improved and survived till discharge, more than half $(52.0 \%$, $53.33 \%$ ) of them were males and had a gestational age of $28-<30$ weeks respectively while no one of them had gestational age from $<24-<26$ weeks. The mean weight of them was $1159.32 \pm 262.8$. As regard degree of bleeding, about two thirds (61.33\%) of them had Grade 1 bleeding, $33.33 \%$ had Grade 2 and only (5.33\%) had Grade 3 while none of them had grade 4. Regarding their medical data, it was found that, forty four percent of them had low (5-7) Apgar scoring, $30.67 \%$ of them receive blood transfusion immediately after delivery and only $(16.0 \%)$ had congenital anomalies. Regarding complications after delivery, the majority $(96.00 \%)$ of them had asphyxia followed by Physiological jaundice $(90.67 \%)$, followed by respiratory distress syndrome $(61.33 \%)$, followed by Pathological jaundice $(37.33 \%)$, then convulsion $(36.0 \%)$.
Table (2): Shows that more than half (53.33\%) of studied neonates mother's were in the age group ranging between $25-<30$ years old. Two thirds $(65.33 \%)$ of them were housewives and $(29.33 \%$, $28.0 \%$ ) of them had secondary and university education respectively and only (10.67\%) were illiterate.

Table (3): Display that all mothers of studied preterm neonates (100\%) had follow up during their pregnancy and the majority (94.67\%) of them had single pregnancy, indeed $(60.0 \%)$ had complication during their pregnancy, bleeding during pregnancy was the most common (38.67\%) complication reported. Although, about two thirds (66.67\%) of them take drugs during their pregnancy, more than half $(56.0 \%)$ of them had chronic diseases. The most common chronic diseases were hypertension and cardiac diseases $(36.00 \%, 32.0 \%)$ respectively .As regard to place and type of delivery, about two thirds $(65.33 \%)$ of them delivered at general hospital and the majority $(93.33 \%)$ were delivered through C.S. 
The vast majority (96.0\%) of them had complications during delivery and the most common complication was pre-term labor $(69.33 \%)$, followed by bleeding during labor $(62.67 \%)$, and followed by bleeding before labor (33.33\%) then PROM (25.33\%).

Table (4): Represent biosocial data of studied nurses. It was found that, more than one third $(37.25 \%)$ of them were in the age group between $30-<40$ yrs. The mean age of them was 29.45 \pm 9.67 . Regarding educational level, marital status and residence, forty one percent of them were have bachelor's of nursing while one third $(33.33 \%)$ of them had diploma of nursing education, about two thirds $(64.70 \%)$ of them were married and more than half $(54.90 \%)$ of them were from urban areas. As regard job level, years of experience and training programs, the majority $(90.20$ $\%$ ) of them were staff nurses and about one third and more $(31.37 \%, 35.29 \%)$ of them have $5-<10$ and 2 $<5$ years of experience respectively. However, no one of them attend previous training program about nursing care for preterm neonates with intraventricular hemorrhage.

Table (5): Depict mean scores of quality of nursing care provided for studied preterm neonates with intraventricular hemorrhage. It was observed that, the overall quality of nursing care provided by the studied nurses for preterm neonates with intraventricular hemorrhage was around average with a mean total score of $38.18 \pm 5.77$. More than half of studied nurses $(50.98 \%, 56.86 \%$ and $58.82 \%)$ in the morning, afternoon and evening shifts respectively had good mean scores of nursing care provided for studied preterm neonates with intraventricular hemorrhage. Meanwhile, $(49.01 \%, 43.13 \%$ and $41.17 \%$ ) of them in the morning, afternoon and evening shifts respectively had poor scores of nursing care while no one of them had excellent scores of nursing care. Also, It was found that the highest quality of nursing care provided (7.67 \pm 5.53 , $7.83 \pm 4.61)$ was related to maintain oxygenation in both afternoon and evening shifts respectively, followed by $(5.40 \pm 0.74,5.00 \pm 0.46)$ was related to feeding in both morning and afternoon shifts respectively, followed by monitoring vital signs and infection control $(5.58 \pm 0.56,4.76 \pm 1.15)$ respectively in the morning shift. On the reverse, levels of quality care of studied nurses in relation to prevention of fluctuations in cerebral blood flow and hygienic care were poor.

Table (6): Projects correlation between total score of quality of care of studied preterm neonates with nurse's education, age and experience years. Positive correlations were found between total score of quality of care provided for studied preterm neonates with nurse's age, years of experience and education with highly statistically significant.

\section{Discussion}

Intraventricular haemorrhage (IVH) remains a serious threat to the survival of premature infants with long term neurodevelopmental outcomes and important effects on morbidity and mortality regardless of advanced technology and better neonatal care. Its incidence increases with decreasing gestational age and birth weight (Huvanandana, et al., 2017 \& Elfarargy, et al., 2017) Thus, special attention should be given to unstable, ill, preterm infants during the first $72 \mathrm{~h}$ after birth, since these are at greatest risk of developing IVH (Adefalujo, et al., 2018)

Measuring the quality of nursing care is an essential part of measuring the quality of the health care provided to neonates because the caring relationships embedded in nursing practice are key, independent factors affecting their outcomes. Hence, improving and sustaining the quality of care in hospitals is a persistent and an intractable challenge (Beattie, et al., 2014 \& Agbele, et al., 2018) Therefore this study highlight the importance to investigate quality of nursing care provided for preterm neonates of low birth weight with intraventricular hemorrhage.

Finding of the present study revealed that out of 75 low birth weight preterm neonates studied, 71 improved and survived till discharge. Consequently, science, technology, professional dedication and advanced skills have made miracles nearly routine in modern neonatal intensive care units (NICU's). When mortality was the primary outcome indicator, any surviving baby was considered a success (Shattuck and Huff, 2015). As regard Personal characteristics of studied preterm neonates, the current study reported that, more than half of studied neonates were males and had a gestational age of $28-<30$ weeks. Seventy two percent of them had a birth weight < $1500 \mathrm{gm}$. These finding are approximately consistent with Christian, et al., (2016) who indicated that fifty-six percent of his study population was males and with that of Schmid, et, al., (2013) researchers who found that Intracranial hemorrhage occurs in $20 \%$ to $25 \%$ of neonates born before the $30^{\text {th }}$ week of gestation or weighing less than 1500 grams at birth, Moreover, Karen, et al., (2017) mentioned that about $20-25 \%$ of the extremely premature infants (gestational age [GA] <28 weeks) will develop IVH with the incidence being inversely proportional to GA while in contrast with Haroon, et al., (2014) who found that there was no gender difference in the occurrence of IVH. These results emphasize the importance that neonates who are born at gestational age younger than 30 weeks should be screened with cranial ultrasound at 7-14 days of age.

Regarding degree of bleeding of studied preterm neonates, about two thirds of them had grade 1 
bleeding, one third had Grade 2 and only five percent of them had grade 3 while none of them had Grade 4 . This finding is apparently similar to Szpecht, et al., (2016) who proved that the majority of cases involving mild bleeding (classified as grade 1 and grade 2), no clinical effects are observed, usually resolve themselves and cause no long-term problems while in contrast with Ahn, et al., (2015) who reported that, in a study of 2386 infants, the incidences of IVH grades 1, 2, 3, and 4 were found to be $25.1 \%, 7.0 \%, 4.8 \%$, and $5.5 \%$, respectively. In addition, according to literature, mild IVH (grade I and II) is more subclinical than severe IVH, but it can also cause long-term neurodevelopment deficits such as impairment of specific cognitive abilities (Haroon, et al., (2014).

As regard, medical data of studied preterm neonates. The present study indicated that, more than half of them had low Apgar score, more than two thirds of them don't receive any blood transfusion immediately after delivery and most of them don't had any congenital anomalies while only $(12.00 \%$, $6.67 \%, 4.0 \%$ ) had shock, sepsis and acidosis respectively. Unfortunately, the vast majority of them had asphyxia and Physiological jaundice and more than two thirds of them had respiratory distress syndrome. These results approximately go on line with recent literature, that the etiologies identified in infants who have experienced IVH include asphyxia, severe respiratory distress, Pneumothorax, Hypoglycemia, shock, acidosis, blood transfusion, seizures and rapid volume expansion (Hockenberry \& Wilson, 2015).

Regarding personal characteristics of mothers of studied preterm neonates. More than half of them were in the age group ranging between $25-<30$ years old, most of them was educated. One possible explanation for this is that education will help them to be able to identify their neonate's health needs and expectations during care for them. In addition, education is a mean that enables mothers to gain access of knowledge and to control many events in their infant's life. However, more than two thirds of them were Housewives. This result insisted the need for health teaching for these mothers because exposure to work outside the home gives them better chances of contact with a more experienced persons and to acquire valuable health and social information. As regard biosocial data of studied nurses, it was noticed that more than one third of them were in the age group between $30-<40$ years old, the mean age were $29.45 \pm 9.67$, about two thirds and more than half of them were married and from urban areas respectively. Unsurprisingly, forty one percent of them had bachelors of nursing and one third were have diploma of nursing education and the majority of them were staff nurses. This can be interpreted by the fact that the graduates from faculty of nursing were in continuous increase and they have the ability to assume all types of neonatal critical care. One third and more of them have $5-<10$ and $2-<5$ years of experience respectively. Despite that, no one of them attend previous training programs about nursing care for preterm neonates with intraventricular hemorrhage. These results were in contrast to that of a cross-sectional study of Lake, et al., (2016) about quality of care in NICU where, almost half (49\%) of nurses held a BSN or higher and had 10.9 years of experience on their current unit.

The current study revealed that, the overall quality of nursing care provided by the studied nurses for preterm neonates with intraventricular hemorrhage was around average with a mean total score of 38.18 \pm 5.77 . Remarkably, results showed that studied nurses have a good quality of care in relation to maintaining oxygenation for studied preterm neonates in both afternoon and evening shifts, followed by feeding in both morning and afternoon shifts, followed by monitoring vital signs and infection control in the morning shift. Another positive finding of this study is that, positive correlations were found between total score of quality of care provided for studied preterm neonates with nurse's age, years of experience and education with highly statistically significant $(\mathrm{P}<0.000, \mathrm{P}<0.000$ \& $\mathrm{P}<0.001)$ respectively. These results yielded that, yet, there was agreement that it should be an explicit standard that: if a qualified nurse staff assumes care, the nurse retains responsibility for ensuring such cares are performed correctly and safely. In addition, NICU neonates are at increased risk for adverse outcomes related to quality and safety (Lake, et al., 2016)

On the other hand, it is observed that, levels of quality care of studied nurses in relation to prevention of fluctuations in cerebral blood flow and hygienic care were poor. Even though, it is an important issue in care of these neonates, in which fluctuations in systemic blood pressure as well as postural changes could lead to alterations in cerebral blood flow (Hockenberry \& Wilson, 2015). One possible explanation for these poor levels of quality care that, there is a distinct lack of detailed practical guidance for IVH nursing standard of care, insufficient knowledge and high burden setting. This emphasizes the importance that nurses need to have academic courses in nursing science related to IVH and increase quantity of nurses in NICU. Hence, in many developing countries, quality of care has not been a priority issue. In addition, rather than remaining in the background, hard to discern, or invisible, the work of nurses must be brought to the foreground so 
that nursing practices may be assessed and measured with clarity and accountability (Awhonn, 2014).

\section{Conclusion}

The study concluded that, the overall quality of nursing care provided by the studied nurses for preterm neonates with intraventricular hemorrhage was around average. Meanwhile, good quality of care were found regarding total level scores of maintaining oxygenation, feeding, monitoring vital signs and infection control while some important issue of care as prevention of fluctuations in cerebral blood flow and hygienic care still need to be improved as it is very important aspect in care of these neonates

\section{Recommendations}

Based on the findings of the present study, the following recommendations are suggested

- Hospital management should develop standards of quality care and procedures in the form of a manual to be available in neonatal intensive care units to all nurses and it should be reviewed regularly and developed according to international standards.

- Providing quality improvement training programs for all nurses working in neonatal intensive care units

- Special attention should be given to unstable, ill, preterm infants during the first $72 \mathrm{~h}$ after birth, since these are at greatest risk of developing IVH.

- Neonates who are born at younger than 30 weeks should be screened with cranial ultrasound at 7 14 days of age and counseling their families highlight the importance of regular long-term follow-up and screening for adverse neurodevelopment outcomes in this population

- Further research is needed in larger groups of extremely preterm infants during the first postnatal days.

Acknowledgement

The author wish to acknowledge all neonatal nurses and neonates' mother's who were participated in the study; for their cooperation to achieve this work.

\section{References}

1. Abd El Fattah, N., \& Zein El Dein, N., (2012): Assessment of Quality of Nursing Care Provided Immediately After Birth At University Hospital. Life Sci; 9 (4): 2115-2126 http://www.lifesciencesite.com. 316

2. Adefalujo, A., Yusuf, A., John, I., Soyebi, K., \& Fajolu, I., (2018): Association between Germinal Matrix Hemorrhage and Perinatal Risk Factors in Preterm Neonates, in a
Southwestern Nigerian Hospital, Journal of Advances in Medicine and Medical Research (JAMMR ) 25(1): 1-11.

3. Agbele , T., Nwambo, J., \& Nwankwo, U., (2018): Patients' Perception of Quality Nursing Care in a Federal Medical Centre SSRG International Journal of Nursing and Health Science (SSRG - IJNHS) - Volume 4 Issue 1. Available at: www.internationaljournalssrg.org

4. Ahn, S., Shim, S., \& Sung, I., (2015): Intraventricular Hemorrhage and Post Hemorrhagic Hydrocephalus among Very-LowBirth-Weight Infants in Korea. J Korean Med Sci 30(1): 52-58.

5. Allen K., (2013): Treatment of intraventricular hemorrhages in premature Infants: where is the evidence? Adv Neonatal Care 13:127-130.

6. Beattie, M., Lauder, W., Atherton, L., \& Murphy, D., (2014): Instruments to measure patient experience of health care quality in hospitals: a systematic review protocol, Syst. Rev. Vol.3: Issue 4. Doi: 10.1186/2046-40533-4

7. Beattie, M., Lauder, W., Atherton, L., \& Murphy, D., (2014): Instruments to measure patient experience of health care quality in hospitals: a systematic review protocol, Syst. Rev. Vol.3: Issue 4. Doi: 10.1186/2046-40533-4

8. Bolisetty, S., Dhawan, A., Abdel-Latif, M., Bajuk, B., Stack, J., \& Lui, K., (2014): Intraventricular hemorrhage and neurodevelopmental outcomes in extreme preterm infants; Pediatrics; 133:55-62.

9. Christian, E., Jin, D., Attenello, F., Wen, T., Cen, S., William J., Mack, W., Krieger, M., M., \& McComb, J., (2016): Trends in hospitalization of preterm infants with intraventricular hemorrhage and hydrocephalus in the United States, 2000-2010 . J Neurosurg Pediatr 17: 260-269. DOI: 10.1007/978-37091-0923-6_34

10. El-Atawi, K., Elhalik, M., Kulkarni, T., Abdelsamed, A., Alexander, L., \& Satyan, A., (2016): Risk Factors, Diagnosis, and Current Practices in the Management of Intraventricular Hemorrhage in Preterm Infants: A Review; Acad J Ped Neonatol. 1(3): 55556

11. Elfarargy, M., Eltomey, M., \& Soliman, N., (2017): Early predictors of neonatal intraventricular hemorrhage; Electron Physician, v.9 (8) PP: 4946-4951.

12. Haroon, A., Maheen, H., Salat, M., Dileep, D., Ahmed, S., Akhtar, A., \& Ali, S., (2014): Risk factors for intraventricular hemorrhage in preterm infants from a tertiary care hospital of 
Karachi, Pakistan , J Pak Med Assoc. (JPMA) ,Vol. 64, No. 10

13. Hockenberry, M., \& Wilson, D., (2015): Wong's nursing care of infants and children, $10^{\text {th }}$ edition; St. Louis, Elsevier .Canada.

14. Huvanandana, J., Nguyen, C., Thamrin, C., Tracy, M., Murray Hinder, M., \& McEwen, A., (2017): Prediction of intraventricular hemorrhage in preterm infants using time series analysis of blood pressure and respiratory signals. Sci. Rep. 7, 46538; doi: $10.1038 /$ srep46538.

15. Inder, T., (2018): "preterm intraventricular hemorrhage /posthemorragic hydrocephalus" In: Volpe's Neurology of the Newborn, $6^{\text {th }}$.volpe JJ(ed). Elsevier, Philadelphia, PP. 637.

16. Karen, A., Annemieke, J., Linda, S., \& Wezel-Meijler, B., (2017): The Effect of Head Positioning and Head Tilting on the Incidence of Intraventricular Hemorrhage in Very Preterm Infants: A Systematic Review; Neonatology; 111:267-279.

17. Kenner, C., \& Ellerbee, S., (2018): Nursing Care of the High Risk Newborn. Chapt. 40, Unit 8: Newborn Complications. In Maternity and Women's Health Care, 11th Edition, Elsevier. pp. $1075-1076$.

18. Lake, E., Hallowell, S., Kutney-Lee, A., Hatfield, L., Del Guidice, M., Ellis, L., Verica, L., \& Aiken, L., (2016): Higher Quality of Care and Patient Safety Associated with Better NICU Work Environments ;J Nurs Care Qual.; 31(1): 24-32. doi:10.1097/NCQ.0000000000000146

19. National Quality Forum, (2011): Nursing care Quality NQF.http://www.quality forum.org/nursing. In12-5-2006

20. Schmid, M., Reister, F., Mayer, B., Hopfner, R., Fuchs, H., \& Hummler, H., (2013): Prospective Risk Factors Monitoring Reduces Intracranial Hemorrhage Rates in Preterm Infants .DtschArztebl Int., 110 (29-30):489496. Doi 10_3238 /arztebl 20130489.

21. Shattuck \& Huff (2015): UTMB Neonatology Manual; neonatal disorders of the newborn at:Manualhttps://www.utmb.edu/pedi_ed/Neona tologyManual/Neurological_Disorders/Neurolo gical_Disorders5.html\#) Created with Soft Chalk /Supporting Infant Neurodevelopment in the ISCU section author: Jan Hunter, OTR $\left(3^{\text {rd }}\right.$ paragraph)

22. Szpecht, D., Szymankiewicz, M., Nowak, I., \& Gadzinowski, J., (2016): Intraventricular hemorrhage in neonates born before 32 weeks of gestation-retrospective analysis of risk factors; Childs Nerv Syst 32:1399-1404).
23. The Association of Women's Health, Obstetric and Neonatal Nurses (AWHONN) (2014): Nursing Care Quality Measurement; JOGNN .Vol. 43 Issue 1 pp.132-133

24. VanAesdale, A., \& Upton, F., (2016): Building Better Baby Brains: The 4B project; NICU Nurse Driven IVH prevention; East Tennessee Children's Hospital (ETCH) Knoxville.TN

25. Zhao, S., \& Akkadechanunt, T., (2011): Patients perception of quality nursing care in a Chinese Hospital. International Journal of Nursing and Midwifery Vol.3 (9), PP.145-149. 